City University of New York (CUNY) CUNY Academic Works

Summer 8-2-2017

\title{
Ecological niche modeling of the genus Papio
}

Amanda J. Fuchs

CUNY Hunter College

\section{How does access to this work benefit you? Let us know!}

More information about this work at: https://academicworks.cuny.edu/hc_sas_etds/210

Discover additional works at: https://academicworks.cuny.edu

This work is made publicly available by the City University of New York (CUNY).

Contact: AcademicWorks@cuny.edu 
Ecological niche modeling of the genus Papio

by

\section{Amanda J. Fuchs}

Submitted in partial fulfillment of the requirements for the degree of Master of Arts (Anthropology), Hunter College

The City University of New York

2017

Thesis Sponsor:

August 4, 2017

Date

August 4, 2017

Date
Christopher C. Gilbert

Signature

Jason M. Kamilar

Signature of Second Reader 
(C) 2017

Amanda J. Fuchs

All right reserved 


\section{Dedication:}

For my mother because she has always supported my dreams and sense of adventure, and has sacrificed for my success. For Patrick, because he is always going on these adventures with me, and picking me up while I stumble on them. Lastly, for Africa, for all its inspiration, love, and amazing people and wildlife. 


\section{Acknowledgments:}

I would like to thank my advisors, Christopher C. Gilbert and Jason M. Kamilar for their support, patience, encouragement and guidance throughout this process. I've learned a great deal from them and look forward to continuing to apply the skills they have taught me in my $\mathrm{PhD}$ career. Thank you to my professors and fellow graduate students with CUNY, particularly at Hunter, for their discourse and support on matters of Anthropology, research, and adapting to graduate school. I would also like to thank the Anthropology Department at Stony Brook University (SBU) and the Turkana Basin Institute (TBI), in particular, my undergraduate advisor John J. Shea and Andreas Koenig. Without the continuous direction and encouragement from the faculty and staff at SBU and TBI in my undergraduate and post-undergraduate career, I would not have the determination and inspiration to pursue this route in Biological Anthropology. Larissa Swedell for granting me the opportunity to work with the Filoha Hamadryas Project in Ethiopia, which contributed to a passion for baboon research. A very special thank you to Teklu Tesfaye, primary field assistant in Ethiopia, who was an amazing educator in all things baboon related, and most importantly a wonderful friend. Lastly, Stephen R. Frost, Leslie F. Marcus, Fred L. Bookstein, David P. Reddy, and Eric Delson for locality dataset which helped make this project possible. 


\section{Table of Contents}

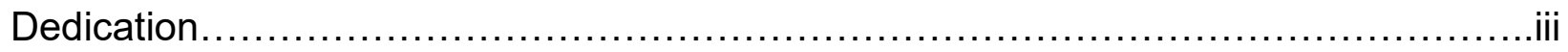

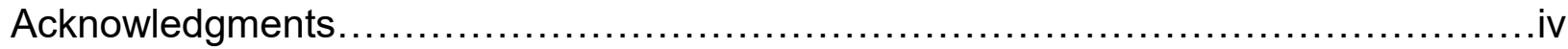

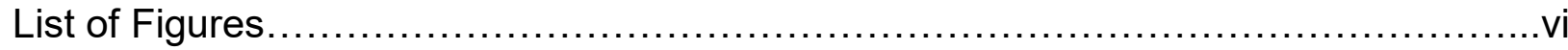

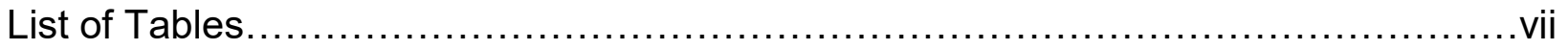

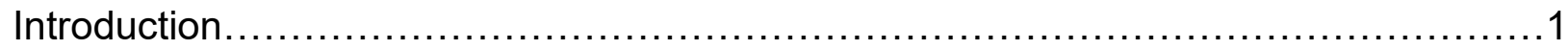

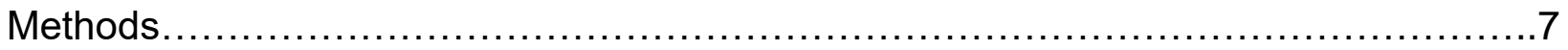

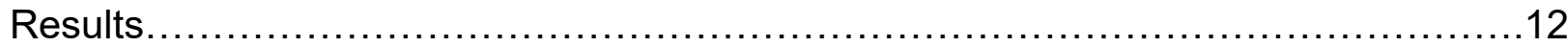

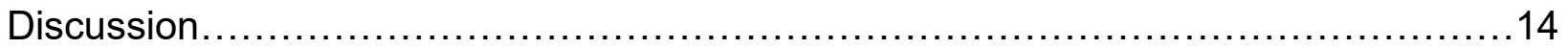

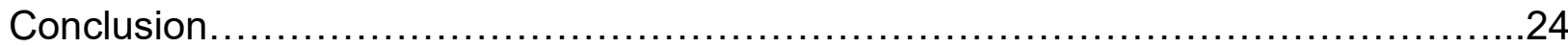

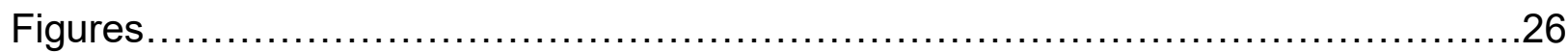

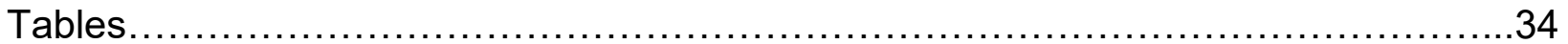

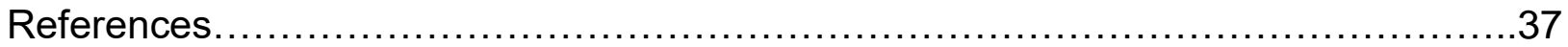




\section{List of Figures:}

Figure 1: IUCN range maps and locality data used in this project.....................26

Figure 2: Guinea baboon (P. papio) ecological niche model..........................27

Figure 3: Kinda baboon ( $P$. kindae) ecological niche model...........................28

Figure 4: Yellow baboon (P. cynocephalus) ecological niche model....................29

Figure 5: Chacma baboon (P. ursinus) ecological niche model........................30

Figure 6: Anubis baboon ( $P$. anubis) ecological niche model..........................31

Figure 7: Hamadryas baboon ( $P$. hamadryas) ecological niche model..................32

Figure 8: Mean area under the curve (AUC) values of four replicates...................33 


\section{List of Tables:}

Table 1: WorldClim BioClim variables applied in models.

Table 2: Mean AUC values and standard deviation.....................................34

Table 3: Binomial test of omission based on minimum training presence. 35

Table 4: Percent contribution of predictor variables. 35

Table 5: Niche Overlap with Hellinger's I. .36

Table 6: Niche Overlap with Schoener's D... 36 


\section{Introduction}

Ecological niche modeling (ENM) is a methodology that is becoming more common in biogeography, ecology and conservation biology in an attempt to understand and estimate the ecological niche and distribution of species. This method has become especially popular since Philips et al's (2006) proposal to use maximum entropy techniques and Elith et al's (2006) improvements with novel methods (for a review on the history of the development and application of ENM packages see Booth et al [2014]). In short, this method combines known species locality data with environmental layers from geographic information systems (GIS), and it has been used to assess speciation, ecological diversity, and niche evolution. Thus, this method is particularly useful for addressing questions on closely related populations or taxa. In recent years, ENM has become even more popular and has begun to be used in the study of primate distributions and adaptations.

For example, ENM has been used recently to assess geographical distribution and taxonomic diversity in primate genera, such as Microcebus and Eulemur in Madagascar (Kamilar and Tecot 2016; Kamilar et al 2016; Blair et al 2013). In the case of Microcebus, the models suggested that climatic variables significantly influence the distribution of five out of the six taxa examined. The sixth species, M. murinus, had a statistically weaker model, suggesting that this species is likely an ecological generalist

less affected by climatic differences. Furthermore, Kamilar et al (2016) suggested that the significantly different niches among Microcebus species provides additional evidence that they are separate species. The Blair et al (2013) study on Eulemur 
suggested that spatial overlap and incomplete geographic boundaries positively correlate with known hybrid zones, and they accurately depicted niche overlap due to climatic similarity. In addition, one pair-wise comparison of species found they resided in notably various environments suggesting that the relationship between these sister taxa was a result of parapatric speciation (Blair et al 2013). Finally, Blair et al (2013) suggested that the remaining comparisons were most consistent with allopatric speciation because there were significant geographic boundaries (i.e. rivers). Ultimately, these studies have shown that by constructing ENM's and assessing the degree of niche overlap the results can provide insight to the mechanisms that have influenced speciation in sister taxa.

The degree to which sister taxa niches are conserved has also been a topic of debate, however, and Warren et al (2008) argue that this may be the result of how niche similarity is measured combined with the null hypotheses being tested. For example, Peterson et al (1999) found that sister taxa have conserved niches and that speciation takes place as a result of geography, with ecological differences evolving later. In contrast, Graham et al (2004) suggest that differential selection plays an important role in differentiation of closely related species because Dendrobatidae, the family commonly referred to as poison dart frogs, inhabited significantly different niches in Ecuador. These varying results could be due to various modes of speciation, but Warren et al (2008) suggest that it may also be a result of various methods, whereby Peterson et al (1999) tested "niche similarity" and Graham et al (2004) tested "niche equivalency." Thus, Warren et al (2008) developed consistent methods which include new similarity metrics and randomization tests to quantify the degree of niche overlap 
among sister taxa. The new metrics applied by Warren et al (2008) compare niche models of species pairs and incorporate Schoener's $D$ statistic (Schoener, 1968), which has been used for a long period of time to assess niche overlap, and Hellinger's I statistic, because it has been used to compare community composition across sites.

Considering that the genus Papio is a widely distributed and studied primate genus, one way to address some questions regarding the complexities of baboon biogeography, evolutionary history and speciation is to construct ENMs. The genus Papio ranges throughout most of Africa, even extending into the Arabian Peninsula, and its species inhabit an array of ecosystems including savannas, open woodlands, semideserts, and swamps (Figure 1) (Kingdon 2009; Altman and Altman 1973). The anubis/olive baboon (Papio anubis) has the largest range and inhabits most vegetation types, including the open savannas and woodlands of East Africa and through the central savanna belt towards the rainforests of western Africa, as well as two isolated populations in Chad and Niger (Groves et al 2001; Newman et al 2004; Burrell et al 2009; Higham et al 2009; Ross et al 2011; Winder 2015; Kunz and Leisenmair 2008). Hamadryas baboons (Papio hamadryas) are found through the semi-deserts of Northeast Africa and the Southwestern region of the Arabian Peninsula dominated by semi-open to closed habitats (Groves et al 2001; Winder 2015). Hamadryas are also known to inhabit coastal lowlands of Eritrea (Zinner et al 2001). West of the anubis baboons' distribution is the smallest Papio species range, Guinea baboons (Papio papio), which are found in more forested, coastal environments (Groves et al 2001; Zinner 2001). Southeast of the Papio anubis distribution is the yellow baboon (Papio cynocephalus) range through eastern and coastal Africa, from Kenya down to Malawi, 
dominated by semi-open habitats (Groves 2001; Winder 2015). Yellow baboons' range has been combined with kinda baboons' (Papio kindae) range in the past (see Newman et al 2004; Burrell et al 2009), which is dominated by semi-open and closed habitats and includes Zambia, Angola, and southern Democratic Republic of Congo (Groves 2001; Winder 2015). Throughout southern Africa, south of the kinda baboons, are the chacma baboons (Papio ursinus), who inhabit semi-open conditions and higher altitudes, such as in the Drakensburg mountains and the areas along the coast surrounding Cape Town, South Africa (Groves 2001; Barrett and Henzi 2003; Hoffman and O'Rian 2012). Thus, because of their wide distribution across many ecotones, baboons are often considered ecological generalists.

Five baboon species have been traditionally recognized: hamadryas baboons, anubis or anubis baboons, Guinea baboons, yellow baboons, and chacma baboons (Groves 2001; Hill 1970). However, in more recent years (and as noted above), morphological and genetic studies have supported the recognition of a sixth species, kinda baboons (Papio kindae) (Szalay and Delson 1979; Jolly et al 2011; Groves 2001; Grubb et al 2003; Zinner et al 2009; Zinner et al 2013). Even though the identification of these six baboon taxa is based on years of research on a variety of biological traits, debate still remains regarding the taxonomic delineation of baboon species. Under a biological species concept (BSC), baboons have been classified as allopatric subspecies of the superspecies P. hamadryas (Jolly 1993; Frost et al 2003). This concept may generalize baboon species, excluding hamadryas baboons, under the broad title "savanna" baboons. For instance, Jolly (1993) hypothesized that that there was little niche separation between baboons and they should be considered subspecies 
(however, it should be noted that his views have recently changed regarding species definitions; see Jolly 2014). Kamilar (2006) examined Jolly's (1993) hypothesis and determined that baboon species inhabit significantly different environments, but that their ecology follows a latitudinal cline, thus resulting in an inability to falsify that there is little niche separation between baboon species. Frost et al (2003) also argued for baboons to be considered subspecies because of latitudinal variation in cranial morphology. Alternatively, baboons have also been considered as six separate phylogenetic species by numerous authors, and this seems to be the growing consensus (Grooves 2001; Grubb et al 2003; Hill 1970; Jolly 2007; Jolly 2013; Zinner et al 2009; Zinner et al 2013). In this thesis, I will adopt the phylogenetic species concept (PSC) and refer to the six baboon taxa as separate species.

Complicating matters of species recognition, known hybrid zones exist where baboon ranges overlap. Baboons are morphologically and geographically distinct species, but exhibit no pre- or post-zygotic reproductive isolation (Zinner et al 2009). This has led to a discordance between mtDNA phylogenies and taxonomy based on morphology, which suggests that reticulation events and introgressive hybridization occurred in baboons' evolutionary history. The confliction between phylogeny and morphology is likely a discordance between mtDNA and nuclear DNA, which results in mitochondrial paraphyly (Zinner et al 2009; Zinner et al 2013). Intrageneric hybridization has been reported between anubis and Northern yellow (Newman et al 2004; Tung et al 2008; Alberts and Altman 2001), anubis and hamadryas (Bergman and Beehner 2003; Bergman and Beehner 2004; Shotake 1981; Bergman et al 2008), kinda and Southern yellow (Burrell 2008), and kinda and grayfoot chacma (Papio ursinus griseipes) (Jolly et 
al 2011). It has also been suggested that hybridization could be occurring between western anubis and guinea baboons (Zinner et al 2009). Intergeneric hybridization in papionins has also occurred, though less common, between Papio hamadryas and Theropithecus (Dunbar and Dunbar 1974; Jolly et al 1997) and Papio and Rungwecebus (Zinner et al 2009b; Roberts et al 2009).

Therefore, despite many years of research on the behavior and ecology of baboons throughout Africa, basic questions still remain as to the forces driving the distribution of these taxa and the exact mode of speciation that appears to be occurring. Therefore, this study represents an effort to examine some of these issues through ecological niche modeling and address the following research questions. First, do climatic variables influence the distribution of the living Papio species? Second, are baboon species ecological generalists or are they more specialized in regards to climate? Finally, what do the data suggest about the mode of speciation in the genus Papio? If climate-based ENM's have strong predictive power, it would suggest that baboon species distributions are strongly correlated with climatic factors. Conversely, if the models perform poorly, it may indicate that species are ecological generalists and their distributions are not strongly correlated climatic variables. In addition, significant ecological niche overlap between Papio species could indicate allopatric speciation events. Alternatively, little niche overlap may be more indicative of a parapatric speciation model. 


\section{Methods}

\section{Data Collection}

Known localities (latitude and longitude coordinates) for each baboon taxon were obtained from published data (Frost et al 2003; Kamilar 2006) supplemented with points personally collected in Awash National Park, Ethiopia ( $P$. hamadryas), and in the Rumphi District of northern Malawi (P. cynocephalus). The minimum distance between points was one kilometer. Sample size varied, but the minimum sample size per taxon was 8 locality points $(P$. anubis $\mathrm{n}=86, P$. ursinus $\mathrm{n}=46, P$. cynocephalus $\mathrm{n}=20, P$. hamadryas $\mathrm{n}=17$, P. kindae $\mathrm{n}=9$, P. papio $\mathrm{n}=8$ ).

Current climatic conditions (i.e. bioclimatic variables) were downloaded from WorldClim (Hijmans et al 2005) at 2.5 arc-minute resolution. Eight climate variables were used as predictors in the models (Table 1). These included BIO1 (Annual Mean Temperature), BIO4 (Temperature Seasonality (standard deviation *100)), BIO5 (Maximum Temperature of Warmest Month), BIO6 (Minimum Temperature of Coldest Month), BIO12 (Annual Precipitation), BIO15 (Precipitation Seasonality (Coefficient of Variation)), BIO16 (Precipitation of Wettest Quarter), and BIO17 (Precipitation of Driest Quarter). These variables were selected because they represent annual extreme highs and lows in temperature and precipitation, and they are representative of the changes in climate that can be observed across a large geographic area, as is the case with the current study. They were also chosen based on baboon physiology and life history. For example, due to the long lifespan and large body size observed in Papio species, 
weekly climate variables were excluded. In addition, three of these climatic variables (Temperature Seasonality, Minimum Temperature of Coldest Month, Precipitation of Driest Quarter) were selected out of the six climatic variables applied in previous ENMs of primates with MaxEnt software (Kamilar and Tecot 2016; Kamilar et al 2016; Blair et al 2013).

\section{Data Analyses}

MaxEnt version 3.3.3k (Phillips et al 2006; Phillips and Dudik 2008; Elith et al 2011) was used to create all species distribution models, with all default options as well as "random seed" selected. A four-fold validation approach was used, which partitions the species occurrence data into four equally sized subsets (Kamilar and Tecot 2016; Blair et al 2013). This step is useful because it allows all data to be used for both training and testing the model (Kamilar and Tecot 2016). The success of the models was judged from two criteria, the first being the "area under the curve" (AUC) statistic and the second being the binomial test of omission under a minimum training presence. AUC values assess a given model's ability to predict a species distribution and range from 0.0 to 1.0. An AUC value of 1.0 indicates that the model perfectly predicted a given species distribution, and that, therefore, the climatic variables strongly influence species localities. A value of 0.5 is equivalent to high levels of model uncertainty, with the climate variables having no predictive ability. Following previous studies, models with AUC values ranging from $0.7-0.8$ were considered moderately good, AUC values ranging from $0.8-0.9$ were considered strong, and models with AUC values above 0.9 were considered to perform extremely well. Mean AUC values for each species were calculated from the four replicate models (Phillips et al 2006; Phillips and Dudik 2008; 
Elith et al 2011; Warren et al 2008; Kamilar and Tecot 2016; Kamilar et al 2016; Blair et al, 2013). To calculate the statistical significance of each model's predictive ability I used the binomial test of omission under a minimum training threshold (Phillips et al 2006; Kamilar and Tecot 2016; Blair et al 2013). The binomial test of omission was considered statistically significant if it had a $p$-value of 0.05 or lower. This test was performed for each replicate model for each species. I used the percent contribution value associated with each predictor to asses which climatic variables had the greatest influence on the model. In addition, response curves were examined to determine how each predictor was related to the probability of suitable habitat.

The geographical regions for analysis were determined by using range maps from the IUCN combined with the locality data referenced above (Figure 1). Areas that baboons are known to not inhabit (e.g. Congo rainforest) were excluded because including these areas would artificially increase the performance of the models. Furthermore, MaxEnt only requires known locality data to construct climate based species distribution models (Phillips et 2004; Phillips et al 2006; Phillips and Dudik 2008; Elith et al 2011), which has made it a common and popular approach to construct ecological niche models in recent years. MaxEnt has also been the preferred method for recent primate studies (Kamilar and Tecot 2016; Kamilar et al 2016; Blair et al 2013). Conversely, criticisms of only using presence data can be found in Yackulic et al (2012), who suggest that a presence-absence framework should be applied whenever possible to avoid making assumptions. Following the previous primate studies referenced above, a presence-only geographic area of interest framework was used in this study. 
ENMTools software was used to examine the degree of climate niche overlap among baboon taxa. The default options were employed, except "MaxEnt version 3.2x or older" was selected. The identity test was performed to assess whether the habitat suitability scores generated in the ecological niche models of two or more species are significantly more different than expected if they were generated from the same distribution. The identity test uses all locality data from both taxa and randomly assigns localities to "pseudo" species pairs. This is done by taking the observed locality points and randomizing the identities to produce a new dataset composed of the same number of localities as the empirical dataset (Warren et al 2008). 99 pseudo species pairs were created, and then the real species pair data were compared to this randomized distribution to determine statistical significance (Warren et al 2008; Warren and Seifert 2010; Warren et al 2011). In addition, the niche overlap function in ENMtools was used to measure the similarity between the predicted habitat of each baboon species pair. Niche overlap for pairwise -species uses Schoener's $D$ (Schoener 1968) and Hellinger's I (Warren et al 2008) metrics which vary from zero to one. A value of zero indicates no niche overlap between taxa, whereas a value of one indicates complete niche overlap (Warren et al 2008; Warren and Seifert 2010; Warren et al 2011). 99 pseudo D and I datasets were generated, and the observed values were then compared to these random distributions to assess statistical significance. A two-tailed test for Hellinger's I and Schoener's $D$ real values was performed for every species pair comparison to assess the degree of niche overlap. When Hellinger's I and Schoener's $D$ observed values fall above the randomly generated values, significant niche overlap between species pairs is indicated. If the observed values fall significantly below the randomly 
generated values, this suggests no significant niche overlap between pairs of species. If the observed values fall above randomly generated valued it would indicate that there was significant niche overlap (Warren et al 2008). With a two-tailed test, the two lowest values and the two highest values out of the 99 randomly generated values are considered significant based on an alpha of 0.05 .

Mantel tests were performed in PAST version 3.13 (Hammer et al 2001) to examine the relationship between niche overlap and phylogeny (Mantel 1967; Warren et al 2008). Time since divergence was used as a proxy for phylogenetic distance to determine any correlation between divergence time and the degree of niche overlap among baboon taxa. For the first matrix, I compiled a climate niche dissimilarity matrix based on Hellinger's $I$. The second matrix consists of averages of the estimated divergence dates among all baboon taxa from Zinner et al (2013). The mtDNA1 data set is the most complete genetic dataset available for baboons, which incorporates as much of their whole genome as possible, thus the divergence dates derived from these data were used as a proxy for phylogenetic distance. In an effort to be conservative and to simplify the complexity of baboon population phylogeny, I selected divergence dates for each species based on the first population to branch off within each species, so that for $P$. ursinus the date for $P$. ursinus South was used, for $P$. cynocephalus the date for $P$. cynocephalus South was used, and for $P$. anubis the date $P$. anubis West was used. A second Mantel test was also conducted using Schoener's $D$ to quantify niche dissimilarity. 


\section{Results}

Based on AUC values, I found that the climate niche models performed moderately to extremely well for all species. The mean AUC for the six baboon species ENMs ranged from 0.727 ( $P$. hamadryas) to 0.949 ( $P$. papio), with an average AUC of 0.869 across species (Figure 8, Table 2). There was more variation in model performance based on the binomial test of omission results. These tests were statistically significant for all four-folds for only one species, P. ursinus. For two species, P. papio and P. cynocephalus, three of the four-folds were significant. One of the fourfolds was significant for $P$. kindae. None of the four-folds were significant for $P$. hamadryas and $P$. anubis (Table 3 ).

Different climatic variables were more or less important in modeling the distribution of the different Papio species (see Tables 4 for Percent Contribution). Based on the percent contribution values, temperature seasonality (BioClim 4) contributed most to the $P$. ursinus (44\%) and $P$. anubis (53\%) predictive models. Precipitation during the driest quarter (BioClim 17) was the most influential predictor for P. kindae (64.5\%) and $P$. papio (31.1\%). The climatic variable that contributed most to the $P$. hamadryas model was annual precipitation (BioClim 12) at 52\%. Lastly, maximum temperature during the warmest month (BioClim 5) contributed the highest percentage to the $P$. cynocephalus with $29.6 \%$. Overall, the percent contribution results show that for two out of the six baboon taxa ( $P$. anubis and $P$. ursinus) temperature seasonality was the most important climatic variable. Precipitation during the driest quarter was also the most important climatic variable for two taxa ( $P$. kindae and P. papio). Interestingly, certain climatic variables were very weak predictors for some taxa. Climatic variables 
that did not contribute to predictive models include: precipitation of wettest quarter for $P$. hamadryas, precipitation seasonality and precipitation of wettest quarter for $P$. cynocephalus, minimum temperature of coldest month, annual precipitation, and precipitation seasonality for $P$. papio, and annual mean temperature, maximum temperature of warmest month, annual precipitation, and precipitation seasonality for $P$. kindae.

The results of the niche overlap tests indicate that most baboon species exhibit significantly different niches based on Hellinger's I and Schoener's $D$ (see Tables 5 and 6 , respectively). However, for two pairwise comparisons the observed $I$-values fell within the random distribution of values: $P$. anubis vs. P. hamadryas and $P$. cynocephalus vs. $P$. hamadryas (Table 5). For Schoener's $D$ the same pairs' observed $D$-values fell within the random distribution (Table 6).

In addition, a non-significant relationship between the divergence time among taxa and their niche overlap was obtained. The results of the Mantel test run between Hellinger's / observed values and estimated divergence date were non-significant ( $r$ value of $0.236, p$-value of 0.205$)$, as well as for Schoener's $D$ (r-value $0.421, p$-value $0.082)$. 


\section{Discussion}

I found that Papio species distributions are highly correlated with climatic variables based on ecological niche models. Furthermore, seasonal variation in temperature and rainfall best predict baboon distributions, but the importance of specific climatic variables vary across species. Most species pairs exhibited significantly different niches, thus challenging the common idea that they are ecological generalists. Therefore, species that were once clumped together as "savanna baboons" inhabit very different niches based on climatic variables, and these differences could have implications for interspecific variation in behavior and other aspects of their ecology. These results also support a parapatric speciation mode with minimal contact zones and incomplete geographic boundaries for the genus Papio. Lastly, there is no significant correlation between the degree niche overlap and estimated divergence dates for Papio species, indicating that niche separation is not a simple result of time and random events. Thus, these results further support the idea that ecological variables have had an effect in driving the differentiation of these taxa and fluctuations in climate may have significantly influenced the taxonomic diversity and complex evolutionary history of Papio species.

The niche overlap tests indicate that most pairwise comparisons fell significantly below the randomly predicted values which indicate that baboons exhibit significantly different niches. Little niche overlap with the lack of distinct and prevalent geographic boundaries implies a parapatric speciation mode for the genus Papio. Thus, similar to Microcebus and Eulemur, environmental determinants such as rainfall and temperature seem to be playing a significant role in Papio speciation process. These results are 
interesting considering Papio is a larger bodied species that may be able to cross more geographic boundaries compared to smaller bodied species. However, the general pattern for pairwise comparisons suggest that species seem to have adaptations to a unique set of climatic variables in their niches. In contrast to the general pattern, two of the pairwise comparisons fell within the randomly predicted values, indicating that species do not have significantly different niches. Both pairwise comparisons included hamadryas baboons. This could be a result of hamadryas baboons' weaker model and over-prediction of their geographic distribution into other ranges. However, one pairwise comparison included anubis baboons. In Awash National Park, Ethiopia there known contact zones where hybridization occurs (Bergman and Beehner 2003; Bergman and Beehner 2004; Shotake 1981; Bergman et al 2008). Therefore, the fact that the observed value fell within the randomly predicted values is likely associated with the hybridization zone that occurs between these two species. Interestingly, other known Papio hybrid zones had significantly little niche overlap. Lastly, there was a slight positive correlation for the Mantel test, but the results were not statistically significant for degree of niche overlap and time since divergence. Though this is speculative, the slight positive correlation could indicate that species pairs are converging on similar niches over time, but the relationship is still unclear and a small sample size may be influencing the weaker results.

The Guinea baboon ( $P$. papio) ENM performed extremely well with a 0.949 AUC value (Figure 2). This indicates that climatic variables are significantly influencing the distribution of the species. The variable with the highest percent contribution is precipitation during the driest quarter (31.1\%), followed by annual mean temperature 
(27.1\%) and maximum temperature during warmest month $(26.1 \%)$ contributing to a total of $84.3 \%$ of the model. This suggests that precipitation and high temperatures are key factors influencing Guinea baboons range. It is further supported by Winders' (2015) recent GIS-based analysis of range characteristics which states that Guinea baboons inhabit areas with the highest annual temperature and second highest annual rainfall out of the six species. Interestingly, Guinea baboons inhabit a range with the highest rainfall seasonality (Winder 2015), but rainfall seasonality contributed $0 \%$ to the model which indicates it is not an important environmental determinant. Precipitation during the wettest quarter also contributed a fair amount to the model (14.1\%) and the response curve suggests that during this time the probability of presence is most suitable between 900-3,000 mm approximately. This could imply that Guinea baboons adapted to a particular threshold of minimum and maximum rainfall, and extremely warm temperature, though there is extreme deviations in maximum temperature during the warmest month. Guinea baboons also inhabit the smallest range, therefore these variables may be acting as constraints to their distribution, which is also supported by Winders' findings that they inhabit the narrowest range of conditions examined in her study compared to other baboon species. However, it has also been suggested that the Dahomey Gap has served as a geographic boundary for the movement of species in Western African (Raxworthy et al 2007). Recent genetic studies on mtDNA have suggested that Guinea baboons are monophyletic, thus their ability to inhabit such unique and specific environmental conditions may be correlated with their divergence from other Papio species and more solitary evolution (Zinner et al 2009, 2013), until 
nuclear DNA becomes available it is difficult to say for certain what the relationship is between genetics and ecology.

Kinda baboons ( $P$. kindae) had the second strongest models at 0.940 AUC (Figure 3). Precipitation during the driest quarter was the most important variable, contributing to more than half of the model $(64.5 \%)$. The response curve for this variable indicates that the probability of suitable habitat is zero when rainfall is from $0-400 \mathrm{~mm}$ per year. A comparative study has suggested that kinda baboons inhabit the one of the cooler ranges with the highest mean annual rainfall (Winder 2015). Since they inhabit cooler, wetter environments it could possibly be linked to the other important environmental predictors with the model, such as minimum temperature during the coldest month (18.3\%) and precipitation during the wettest quarter (17.1\%). In fact, probability of suitable habitat was strongest above $750 \mathrm{~mm}$ for precipitation during the wettest quarter. These few contributing factors to kinda baboon distribution could then have implications for kinda baboon thermoregulation and socio-ecology. For example, previous studies have shown that primates may be influenced by colder, wetter climates which put them at risk for frost or decreased activity in heavy rainfall (Kamilar et al 2016; Higham et al 2009; Hill et al 2003). The five other variables contributed $0-0.1 \%$ to the model, two of these variables included temperature and rainfall seasonality. Winder (2015) argues that kinda baboons have little environmental variability comparatively, if so, this could explain why seasonality predictors did not contribute to the model. However, to better understand the role of environmental variables on kinda baboon behavior and ecology more extensive research must be conducted. Ultimately, the strength of the model and minimal niche overlap results in this project suggest that this 
species is inhabiting a distinct niche compared to other baboon species and further supports its recognition as a sixth baboon species.

Yellow baboons ( $P$. cynocephalus) had an AUC of 0.833 which is a strong model (Figure 4). The model accurately depicted their distribution throughout eastern and central eastern Africa, along the coast, in their known range. Their most suitable habitats are through Kenya and Tanzania (which in part could be due because of a sampling bias of locality data towards northern sites), but extends south towards Malawi. Yellow baboons were also predicted on the opposite coast in western Africa, northwest of the kinda baboons range in Angola, Democratic Republic of Congo, Republic of Congo, and Gabon where there are no known baboon populations. However, they were not predicted within the kinda baboons' range, an interesting result considering that kinda baboons were long recognized as a subspecies of yellow baboons. Yellow baboons inhabit lower latitudes with cooler environments compared to hamadryas, anubis, and Guinea (Winder 2015), which compliments what model results suggest about temperature mainly influencing the distribution of this species. The most important predictor was maximum temperature during the warmest month $(29.6 \%)$ and probability of suitable habitat begins to decline above 32 degrees $C$. This is followed by temperature seasonality and minimum temperature during the coldest month, which suggests the most suitable temperatures range from 13-23 degrees $C$. These three variables totaled $83.4 \%$ of the model, which indicates that temperature is a driving force for yellow baboon distribution. Interestingly, Winder (2015) stated that what made the yellow baboons range "distinctive" compared to other baboons' ranges was that yellow baboons had the "lowest overall temperature seasonality." This seems to contradict, yet 
complement, these results considering temperature seasonality contributed $27 \%$ to the model, suggesting fluctuations in temperature are important. However, the response curve for this variable suggests that minimal temperature seasonality is most suitable.

Chacma baboons ( $P$. ursinus) had the next strongest model with AUC of 0.882 (Figure 5). Temperature seasonality is the most important predictor, contributing to more than half of the model (53\%), whilst temperature in the warmest month $(26.5 \%)$ is the second more important. Considering that chacma baboons inhabit a range with the coldest annual temperatures (19.5 degrees C) and highest seasonal variation (Winder 2015), and considering it has been argued that they have a preference for colder environments (Henzi and Barrett 2003), it suggests that temperature variation is a key factor in chacma baboon distribution. The response curves show that probability of presence is greater with increased temperature seasonality. Whereas maximum temperature during the warmest month illustrates that the most suitable temperature ranges from 5-30 degrees $\mathrm{C}$. Furthermore, annual temperature response curves suggest suitability begins to decline at 20 degrees $C$. This indicates that chacma baboons are better adapted for cooler environments and potentially at higher altitudes. However, previous spatial modeling of chacma baboons in southern Africa found that they preferred low altitude with cool temperatures and moderate rainfall, and may only be using the mountains (e.g. Drankensburg) as a result of human modification (Stone et 2013; Stone 2012). Also, research on human-baboon conflict in Cape Town, South Africa shown that chacma baboons are selecting human modified environments and resources even when natural resources at higher elevations are available. Thus, this group has not shifted their range into the mountains to avoid humans (Hoffman and 
O'Rian 2013). Therefore, even when human modification is considered, it seems likely that chacma baboons are better adapted to colder environments prior to anthropogenic impacts.

Anubis baboons ( $P$. anubis) had an AUC of 0.795 , which is considered a moderately performing model (Figure 6). This suggests that anubis baboons are more ecologically flexible compared to other baboon species (excluding hamadryas who had a slightly AUC value). However, the suitable habitat throughout East Africa indicates that this region is the most suitable for anubis baboons, even though locality data from throughout their range was used to construct models. In contrast, there are large areas of high uncertainty throughout central and western Africa that could be a result of this species inhabiting the largest range with the most climatic variability. However, the most important predictor was temperature seasonality (43.6\%) and its response curve proposes that environments are more suitable with lower temperature seasonality. This could be linked to the uncertainty in other portions of their range with greater climatic variability and further support more ecological flexibility in this species. Rainfall variables also have implications for anubis baboon distribution as well. The following precipitation variables (combined contribution to the model $35.2 \%$ ) suggest probability of suitable habitat is highest for precipitation during the driest between $50-300 \mathrm{~mm}$, and annual rainfall is least suitable at $250 \mathrm{~mm}$ and most suitable at $600 \mathrm{~mm}$. Research on western populations is more limited, but it reveals that anubis baboon inhabit higher rainfall level at a cost. Higham et al (2009) assessed life-history and rainfall in Gashaka Gumti National Park, Nigeria and argued that rainfall could have significant implications for life history in anubis baboon populations of this region. Furthermore, that the wild troop at 
this study site likely represent the extent of which anubis baboon populations can tolerate particular rainfall conditions and this may explain why, along with competition with more specialized rainforest primates, baboon populations are not present in rainforest of the Congo Basin.

Hamadryas baboons ( $P$. hamadryas) had the weakest model with a $50 \%$ uncertainty in their models and an AUC of 0.762 (Figure 7). Though this AUC value is accepted as a moderately performing model, there are a variety of factors that may explain its weaker performance compared with the other species models. For example, the Malagasy primate, Microcebus murinus, was associated with a weak model and the authors argued it was a result of this species being an ecological generalist, and that abiotic factors have not been strong selective pressures influencing their evolution and distribution (Kamilar et al 2015). Similarly, these results could suggest that hamadryas baboons are more ecologically flexible than is generally appreciated. This ecological flexibility could be associated with their social system. Hamadryas baboons have a multi-level society consisting of the smallest group OMUs, clans, bands, and the largest group a troop (Kummer 1968; Abegglen 1984; Swedell and Schreier 2009; Chowdury et al 2015). Studies suggest that this fission-fusion of social groups may be a coping mechanism to deal with food scarcity (Kummer 1968; Jolly 1993; Schreier and Swedell 2012). Thus, this behavioral adaptation to divide into smaller units during times food scarcity may provide this species with the ability to cope with seasonal fluctuations in temperature and precipitation as food availability increases and diminishes. Food availability likely correlates with annual precipitation being the most important variable, since rainfall is often a proxy for primary productivity and may have implications for 
baboon ecology (Hill et al 2003; Deshmukh 1984; le Houerou 1984). However, even though the model results suggest that this species is an ecological generalist regarding climate, the response curves for temperature and precipitation seasonality suggest that the most suitable habitat for hamadryas baboons has lower seasonality. Additionally, there are portions of the model that show suitable habitat based on the climatic variables, near their known range in Turkana Basin, Kenya. However, this region in occupied by anubis baboons. Therefore, one possibility is that competitive exclusion with anubis baboons could play a role in hamadryas baboons inability to inhabit this area. Another possibility may be that due to their most recent divergence hamadryas have not had the time to disperse further than their known range yet. Lastly, the higher percentage of uncertainty of suitable habitat may also be linked to small sample size.

Overall, the strong ENM results indicate that at the species level, baboons are more specialized in regards to climate than was once thought, and yet there are some notable discrepancies as well. For example, over-predictions of one species into another species range and vice versus was most apparent in two pairs, the Guinea and kinda baboons, and the hamadryas and chacma baboons. Guinea baboons range has the second highest annual mean rainfall (after kinda baboons with the highest) and highest rainfall seasonality (Winder 2015). Guinea and kinda baboons also share precipitation during the driest quarter as the most important climatic predictor for each model. Thus, the kinda baboons' ENM over-prediction into the Guinea baboon range likely correlates with the ability to live in wetter environments. However, the Congo Basin rainforest are not suitable habitat for kinda baboons, thus posing as a geographic boundary. Alternatively, Guinea baboons were not predicted in kinda or any other 
baboons range. Lastly, Guinea and kinda baboons have the two smallest sample sizes, a fact that could influence the strength of the models. In particular, kinda baboon locality data represents a limited portion of their known range, thus, more extensive sampling from throughout their range could provide stronger insight to how climatic variables are influencing the distribution of this species.

Similarly, hamadryas and chacma baboons inhabit the highest and second highest mean altitude of $1,010.3 \mathrm{~m}$ and $984.4 \mathrm{~m}$, respectively, with the highest temperature seasonality (chacma $=3,728.4$ arbitrary units) and third highest temperature seasonality (hamadryas $=2,131.8$ arbitrary units) (Winder 2015). Though altitude was not a variable incorporated in these ENMs, it correlates with temperature seasonality, an important climatic predictor for each species as shown in with the ENM results. Therefore, the over-prediction of hamadryas into chacma range likely has to do with their ability to inhabit similar climatic conditions with lower annual rainfall in higher altitudes influence on their distributions. Annual mean rainfall is approximately less than half for hamadryas and chacma ranges compared to the other four species (hamadryas $=462.6$, chacma $=513.4$, yellow $=899.2$, anubis $=969.8$, Guinea $=1,050.6$, kinda $=$ 1,228.3) (Winder 2015). Furthermore, rainfall seasonality was one the lowest end of the spectrum for hamadryas and chacma ranges (Winder 2015) and contributed less than $2 \%$ to the models. Ultimately, similarities in rainfall, altitude, and seasonality within hamadryas and chacma ranges, as shown by Winder (2015), as well as shared most important climatic predictor for hamadryas and chacma baboons support the notion that these species are more well adapted to drier environments and higher altitudes, which may have significant implications for their evolution and ecology. 


\section{Conclusion}

The radiation of the genus Papio throughout Africa is a fairly recent event beginning approximately $2 \mathrm{Ma}$ (Newman 2004, Zinner et al 2009), and both phylogenetic and fossil evidence suggests that this radiation has southern African origins (Zinner et al 2009; Zinner et al 2013; Gilbert 2008; Gilbert et al 2015). This ability to rapidly disperse and inhabit an array of habitats, and seemingly different niches between species, makes the evolutionary history of Papio both interesting and complex. Though it is likely that there will always be debate regarding baboon taxonomy, ecological niche modelling has been able to shed light on the distribution and delineation of baboon species. The fact that baboon populations inhabit distinct niches with little niche overlap, and that climatic variables are strongly influencing their distribution, suggests that they are more specialized to particular environmental conditions than once was thought. These data combined with behavioral, morphological and phenotypic variability suggests they could be recognized as species, as is current practice. However, multiple clades or haplogroups that outnumber baboon morphotypes (Zinner et al 2009; Zinner et al 2013; Zinner et al 2015) along with hybridization complicates the matter by making it difficult to make distinctions. But what does seem apparent is that environmental variables have long influenced the evolution of baboons. Furthermore, hybridization collated with the differentiation in niches, minimal niche overlap and clinal variation in Papio biogeography seems to indicate that the speciation process may still be occurring.

Future studies may include building models with reconstructed past climate data to better understand how earlier baboon populations were impacted by the last 
interglacial (120-140 ka) and last glacial maximum (21 ka). In addition, constructing models with predicted future climate data may provide insight to how global climate change and anthropogenic impacts may influence baboon populations of the future in regards potential shifting ranges and may even aid human-wildlife conflict management. Furthermore, ENMs of baboon subspecies may provide insight to how intraspecific climatic variation within a species range may be influencing distribution and delineation within a taxon, whilst also shedding light on earlier speciation processes. 


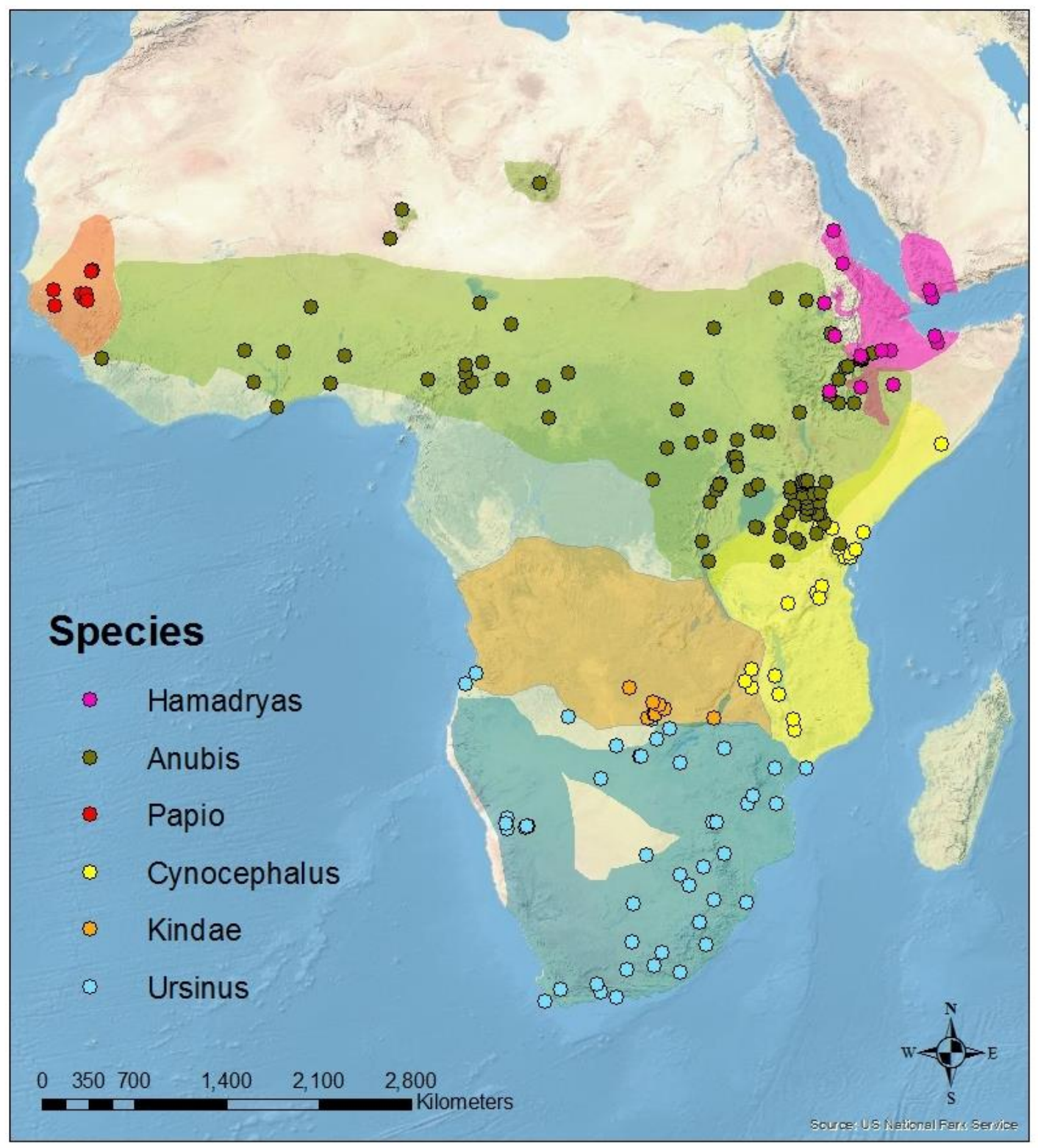

Figure 1: IUCN range maps and locality data used in this project. $P$. anubis: $\mathrm{N}=86, P$. cynocephalus: $\mathrm{N}=20, P$. hamadryas: $\mathrm{N}=17, P$. kindae: $\mathrm{N}=9, P$. papio: $\mathrm{N}=8, P$. ursinus: $\mathrm{N}=$ 46. 


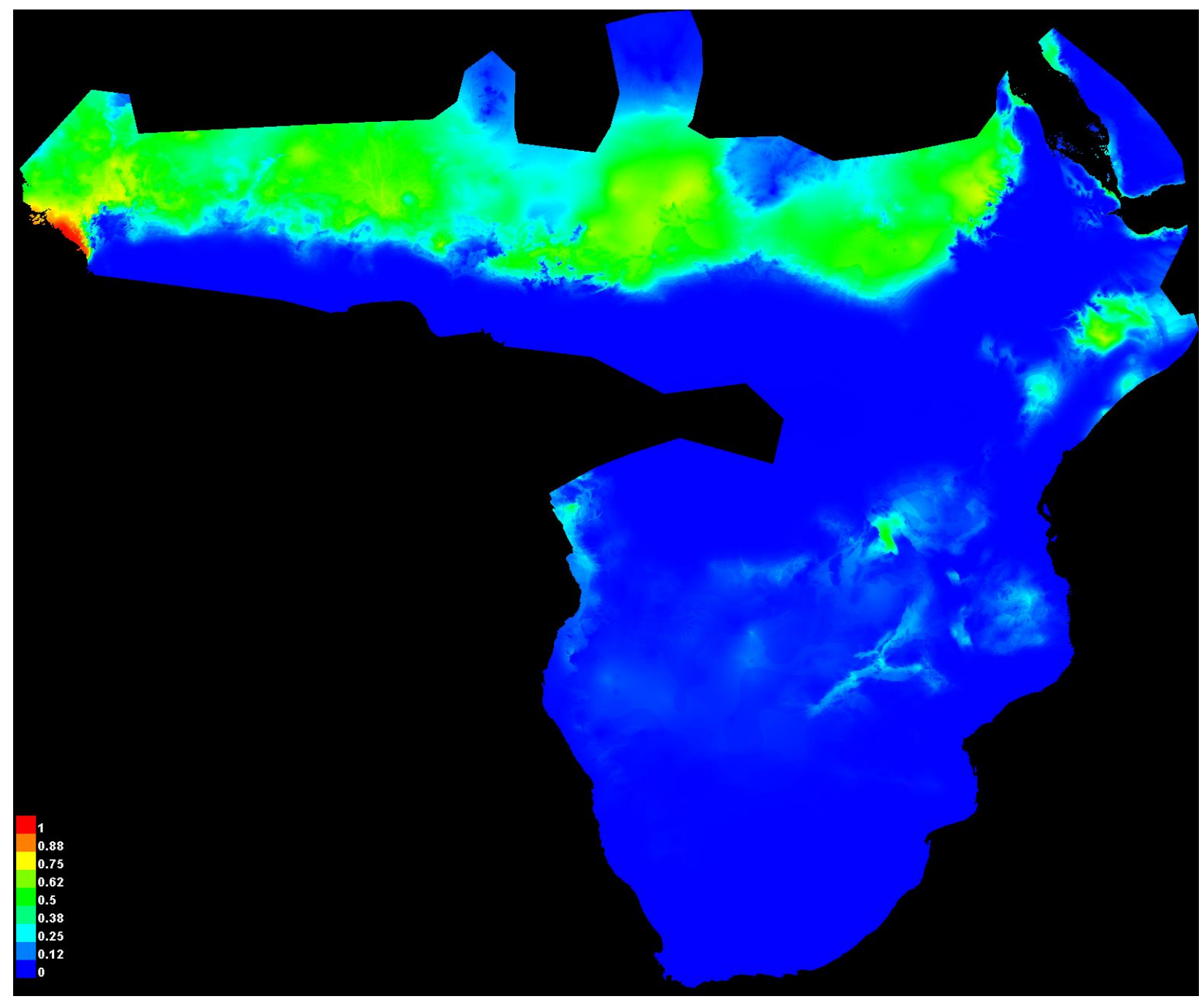

Figure 2: Guinea baboon (P. papio) mean AUC 0.949

Most important predictor: Precipitation Driest Quarter 31.1\% 


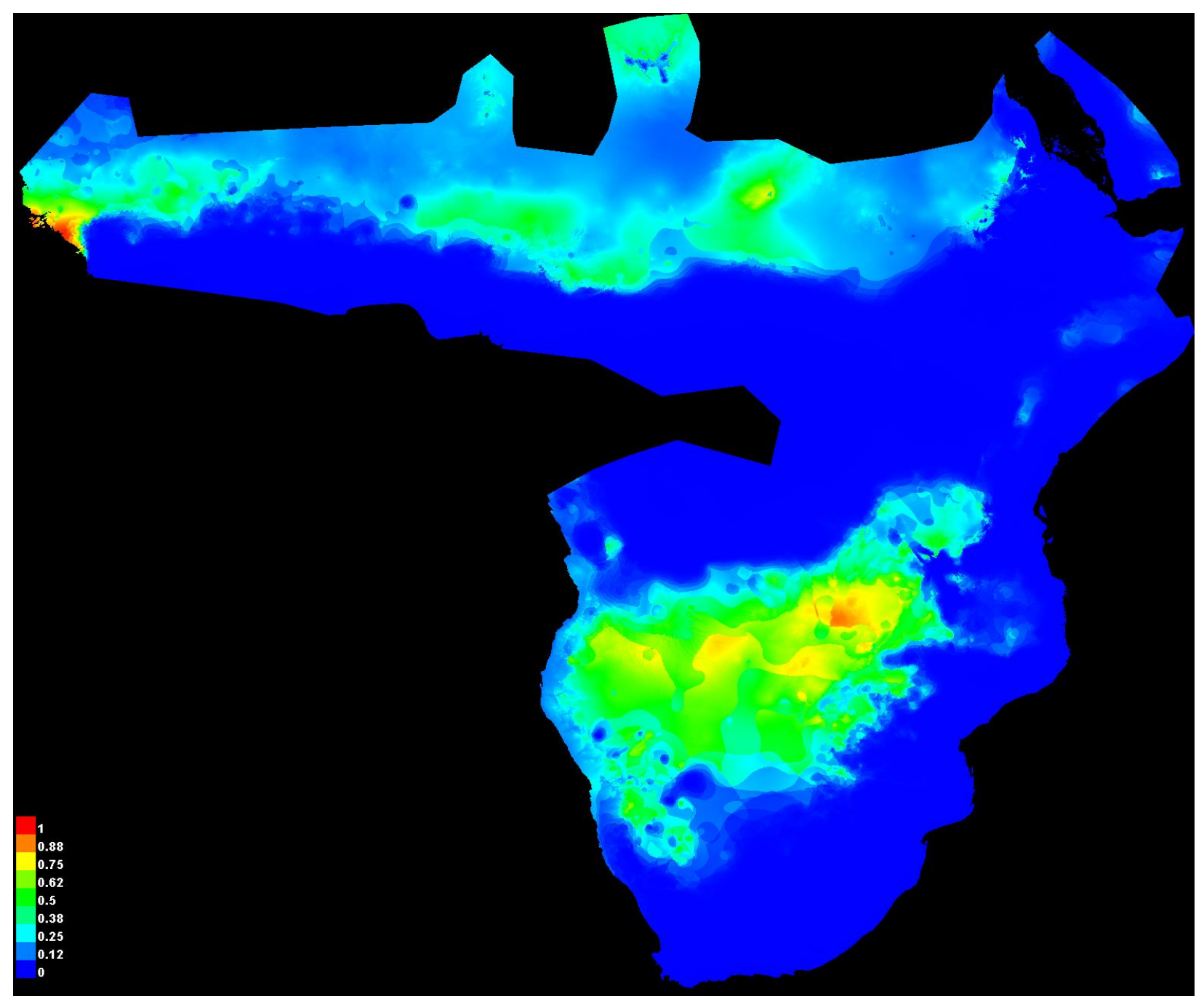

Figure 3: Kinda baboon (P. kindae) mean AUC 0.940

Most important predictor: Precipitation Driest Quarter 64.5\% 


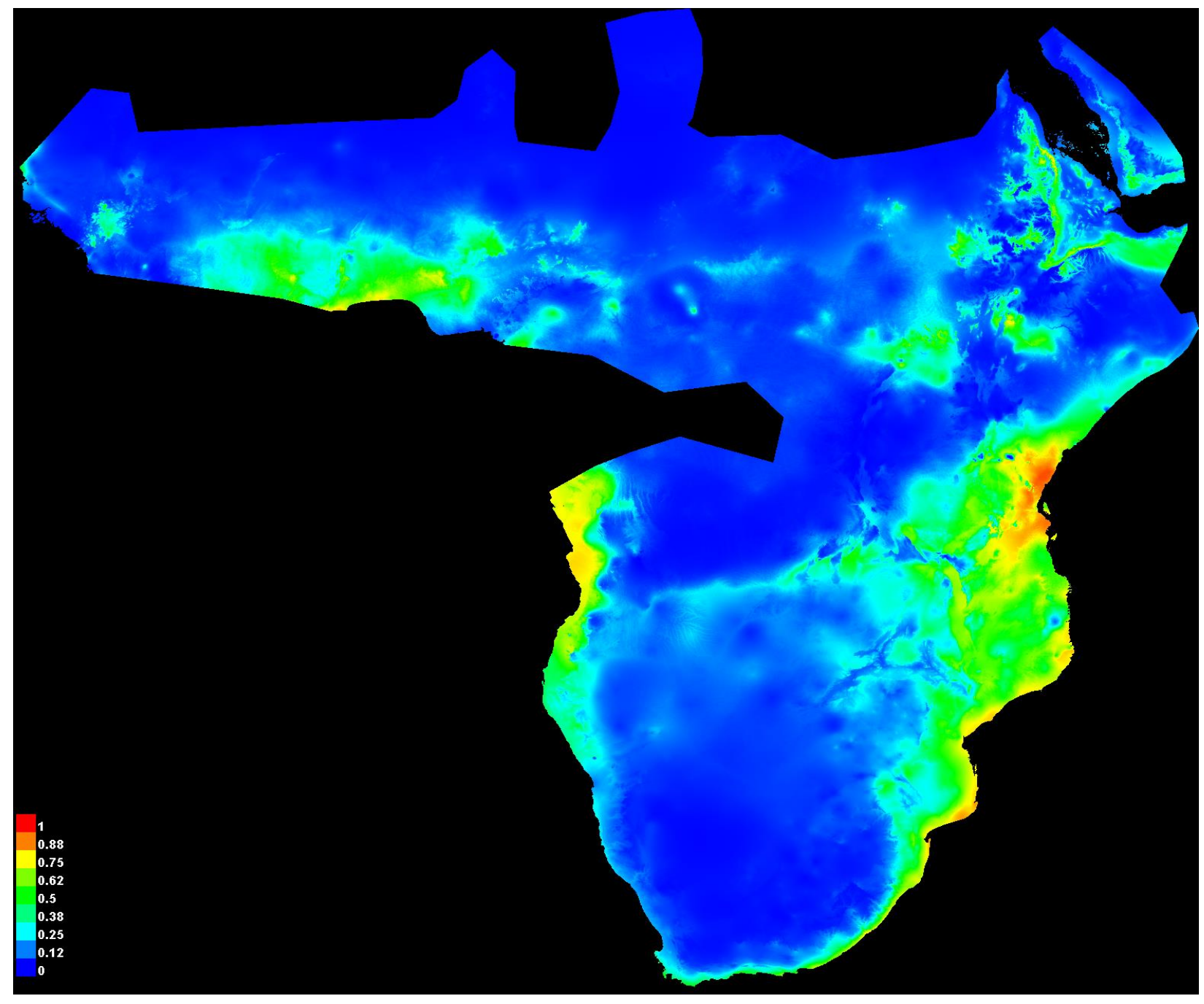

Figure 4: Yellow baboon (P. cynocephalus) mean AUC 0.883

Most important predictor: Maximum Temperature Warmest Month 29.6\% 


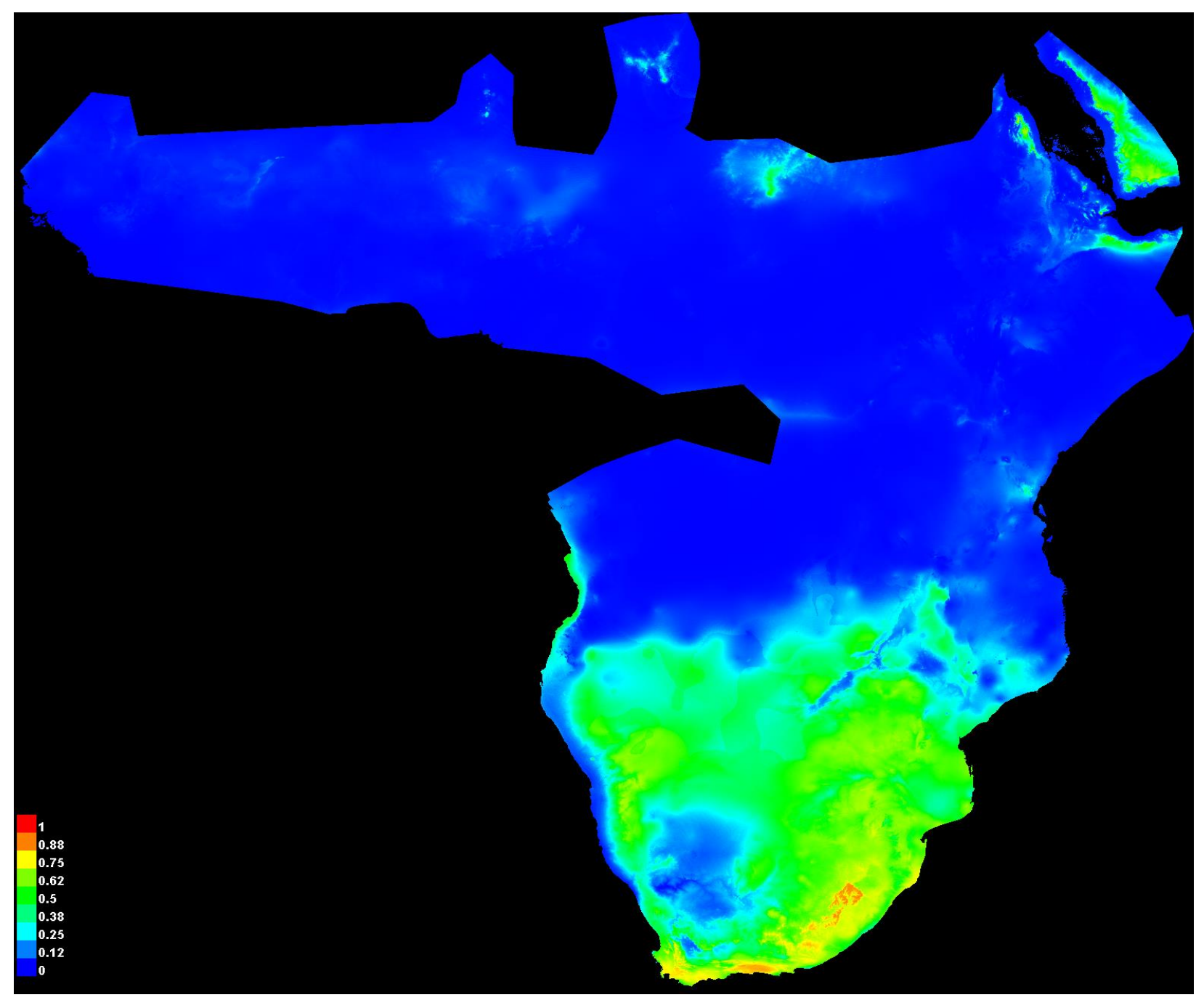

Figure 5: Chacma baboon (P. ursinus) mean AUC 0.882

Most important predictor: Temperature Seasonality 53.4\% 


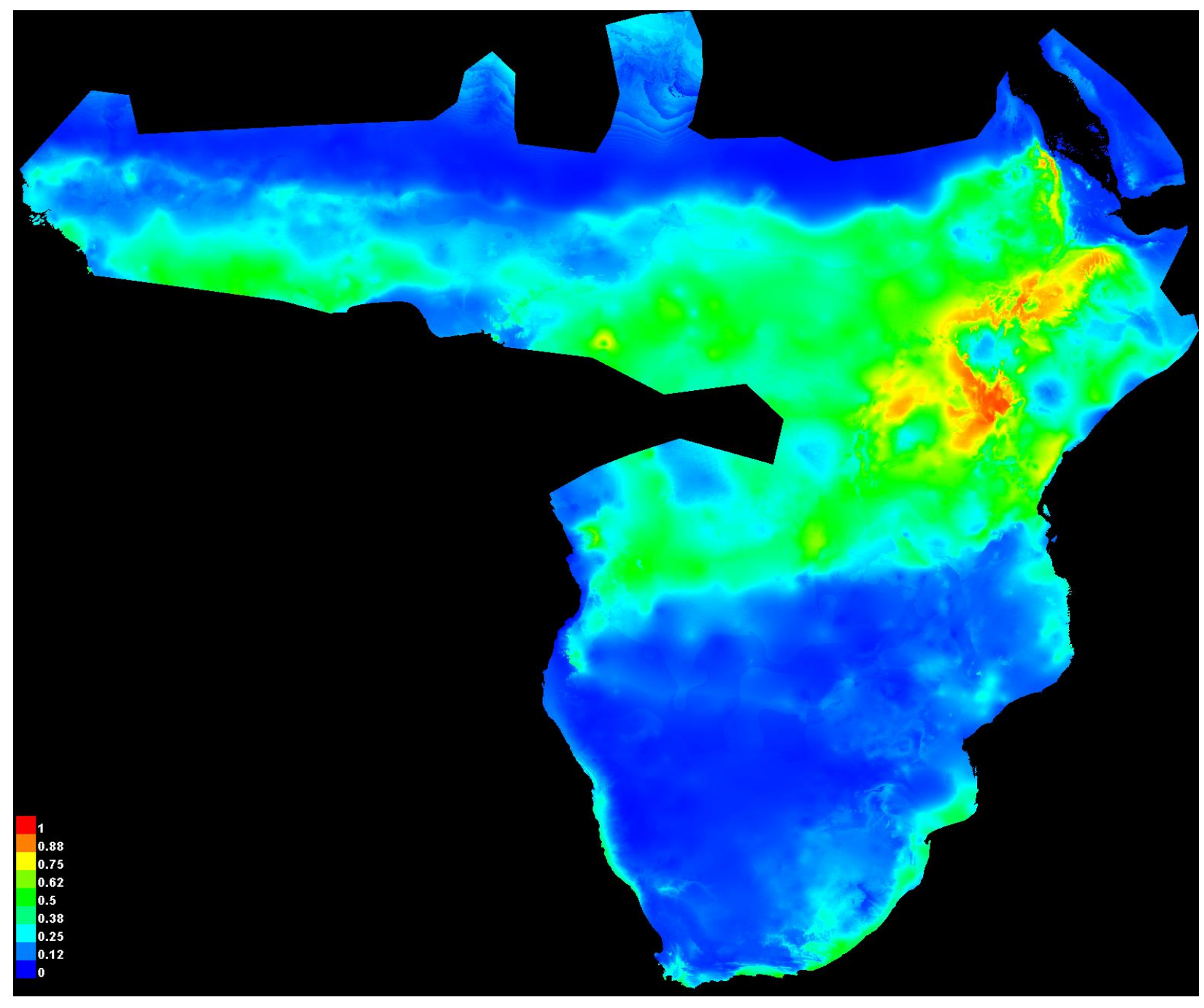

Figure 6: Anubis/Olive baboon (P. anubis) mean AUC 0.795

Most important predictor: Temperature Seasonality $43.6 \%$ 


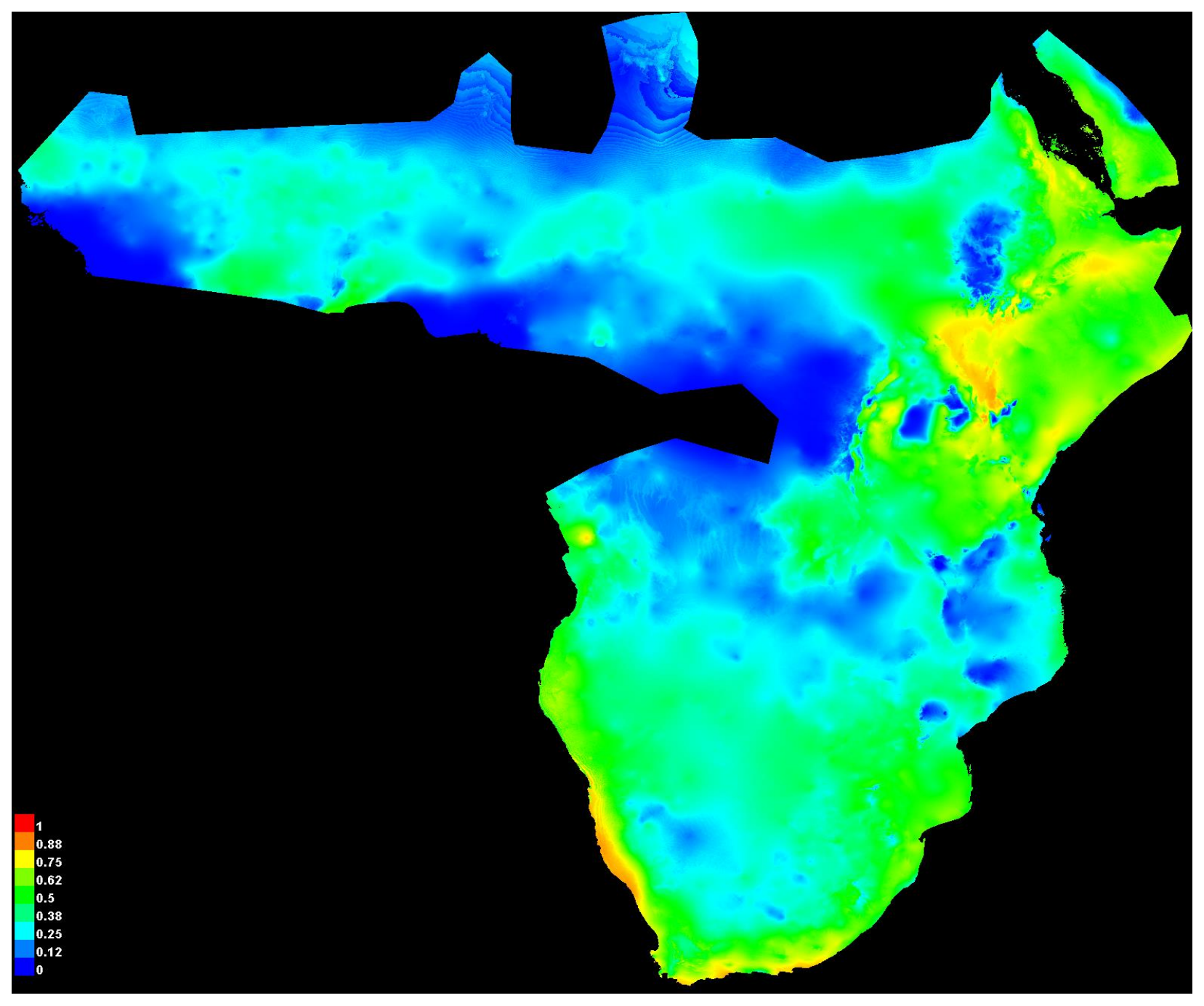

Figure 7: Hamadryas baboon (P. hamadryas) mean AUC 0.762 Most important predictor: Annual Precipitation 52\% 


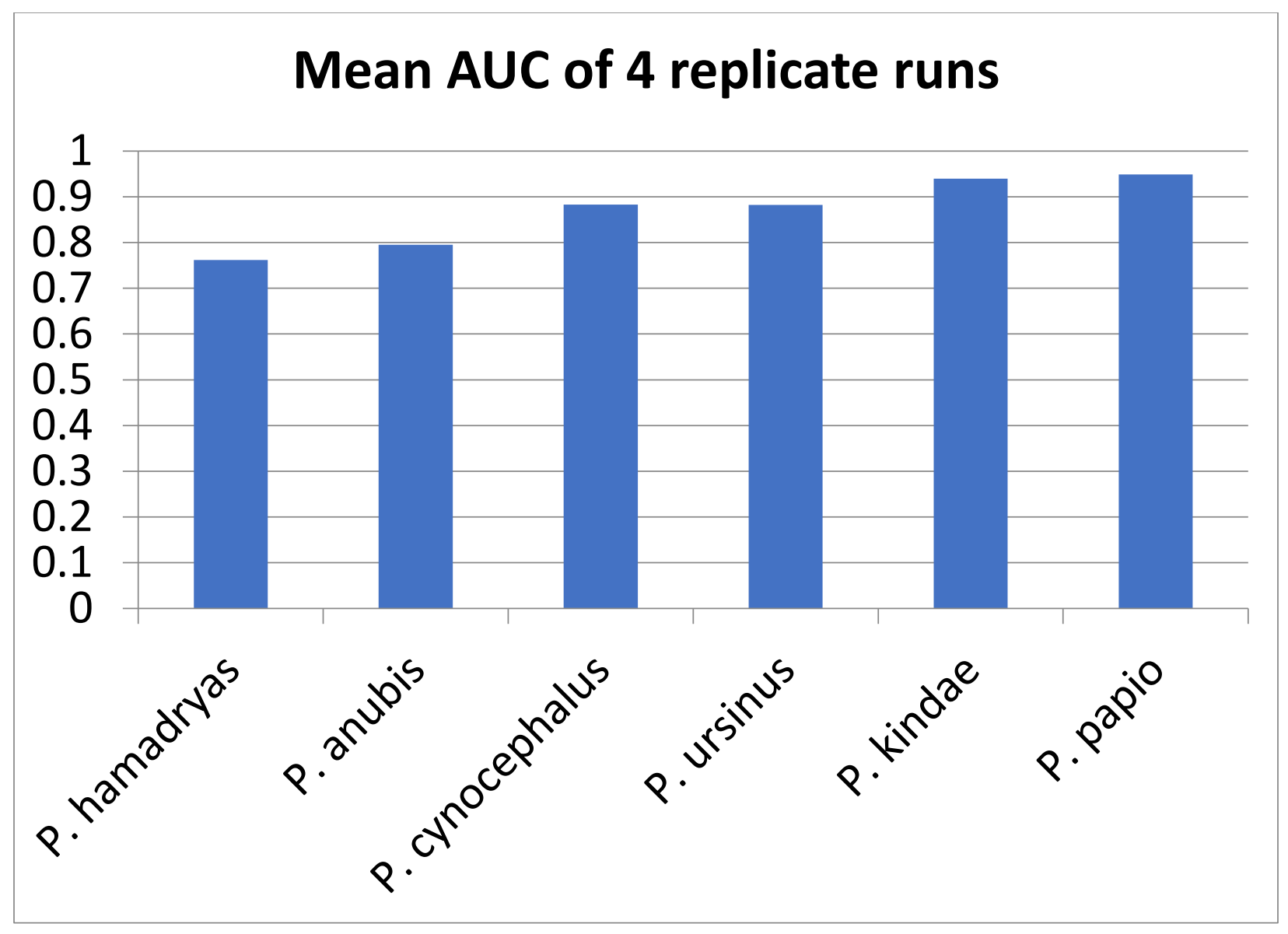

Figure 8: AUC values closer to 0 would indicate that the ENMs could not predict distribution based on the climatic variables, which suggests that species are ecological generalists. The closer the AUC value gets to 1.0 the greater the predictive power of the model, which suggest climatic variables influence the distribution. A value of 1.0 would indicate that the model predicted perfect distribution of taxa based on the variables. A value of .5 is equivalent to a random prediction of species distribution and anything .8 or above is considered strong predictive power. 
Table 1: WorldClim BioClim variables applied in models.

\begin{tabular}{|l|}
\hline BioClim 1 = Annual mean temp \\
\hline BioClim 4= Temp seasonality \\
\hline BioClim 5 = Max temp warmest month \\
\hline BioClim 6 = Min temp coldest month \\
\hline BioClim 12= Annual precipitation \\
\hline BioClim 15 = Precipitation seasonality (C of V) \\
\hline BioClim 16 = Precipitation wettest quarter \\
\hline BioClim 17= Precipitation driest quarter \\
\hline
\end{tabular}

Table 2: AUC values and standard deviation per species, as well as mean AUC across species.

\begin{tabular}{|l|l|l|l|}
\hline Species & $\begin{array}{l}\text { Number of } \\
\text { localities }\end{array}$ & AUC (Mean) & AUC SD \\
\hline P. hamadryas & $\mathbf{1 7}$ & 0.762 & 0.060 \\
\hline $\boldsymbol{P .}$ anubis & $\mathbf{8 6}$ & 0.795 & 0.030 \\
\hline $\begin{array}{l}\boldsymbol{P} . \\
\text { cynocephalus }\end{array}$ & $\mathbf{2 0}$ & 0.883 & 0.047 \\
\hline $\boldsymbol{P .}$ ursinus & $\mathbf{4 6}$ & 0.882 & 0.009 \\
\hline $\boldsymbol{P}$ kindae & $\mathbf{9}$ & 0.940 & 0.059 \\
\hline $\boldsymbol{P}$ papio & $\mathbf{8}$ & 0.949 & 0.026 \\
\hline Mean AUC & & 0.868 & \\
\hline
\end{tabular}


Table 3: Binomial test of omission based on minimum training presence.

\begin{tabular}{|l|c|c|c|c|c|c|c|c|}
\hline Species & $\begin{array}{c}\text { Fold_0 } \\
\text { rate }\end{array}$ & P-value & $\begin{array}{c}\text { Fold_1 } \\
\text { rate }\end{array}$ & P-value & $\begin{array}{c}\text { Fold_2 } \\
\text { rate }\end{array}$ & P-value & $\begin{array}{c}\text { Fold_3 } \\
\text { rate }\end{array}$ & P-value \\
\hline $\boldsymbol{P}$. hamadryas & 0 & 0.2436 & 0 & 0.6779 & 0 & 0.0775 & 0 & 0.2886 \\
\hline $\boldsymbol{P}$. anubis & 0 & 0.3059 & 0 & 0.0885 & 0 & 0.4225 & 0 & 0.1563 \\
\hline $\boldsymbol{P}$. cynocephalus & 0 & 0.0103 & 0 & 0.0185 & 0 & 0.0303 & 0 & 0.0919 \\
\hline $\boldsymbol{P}$. ursinus & 0 & 0.0000 & 0 & 0.0000 & 0 & 0.0008 & 0 & 0.0000 \\
\hline $\boldsymbol{P}$. kindae & 0 & 0.0153 & 0 & 0.0808 & 0 & 0.0739 & 0 & 0.1843 \\
\hline $\boldsymbol{P}$. papio & 0 & 0.0039 & 0 & 0.0069 & 0 & 0.0078 & 0 & 1 \\
\hline
\end{tabular}

Table 4: Percent contribution of predictor variables for each species' distribution model.

\begin{tabular}{|c|c|c|c|c|c|c|c|c|}
\hline Species & BioClim1 & BioClim4 & BioClim5 & BioClim6 & BioClim12 & BioClim15 & BioClim16 & BioClim17 \\
\hline \hline P. anubis & 1 & 43.6 & 4.2 & 4.5 & 15.4 & 1.5 & 10.1 & 19.8 \\
\hline P. hamadryas & 2.5 & 19.5 & 2.3 & 0.2 & 52 & 20.6 & 0 & 2.9 \\
\hline $\begin{array}{c}\text { P. } \\
\text { cynocephalus }\end{array}$ & 0.5 & 27.3 & 29.6 & 26.8 & 7.8 & 0 & 0 & 7.9 \\
\hline P. ursinus & 7.8 & 53.4 & 26.5 & 1.1 & 1.8 & 0.9 & 1.6 & 6.9 \\
\hline P. kindae & 0 & 0.1 & 0 & 18.3 & 0 & 0 & 17.1 & 64.5 \\
\hline P. papio & 27.1 & 0.9 & 26.1 & 0 & 0 & 0 & 14.8 & 31.1 \\
\hline
\end{tabular}


Table 5: Niche Overlap with Hellinger's I

Above the diagonal is Hellinger's I observed values, below the diagonal are the corresponding p-values. Most pair-wise comparisons fell significantly below 100 randomized values, indicating that there is little niche overlap. Two comparisons, both including hamadryas baboons, fell within the range of random values.

\begin{tabular}{|l|c|c|c|c|c|c|}
\hline \multicolumn{1}{|c|}{ SPECIES } & $\boldsymbol{P}$. anubis & $\begin{array}{c}\boldsymbol{P} \text {. } \\
\text { cynocephalus }\end{array}$ & $\boldsymbol{P}$. papio & $\begin{array}{c}\boldsymbol{P} \text {. } \\
\text { hamadryas }\end{array}$ & $\boldsymbol{P}$. kindae & P. ursinus \\
\hline $\boldsymbol{P}$. anubis & 1 & 0.830 & 0.543 & $\mathbf{0 . 8 9 5}$ & 0.497 & 0.533 \\
\hline $\begin{array}{l}\boldsymbol{P} \text { cynocephalus } \\
\text { cy. papio }\end{array}$ & 0.04 & 1 & 0.473 & $\mathbf{0 . 8 6 0}$ & 0.530 & 0.679 \\
\hline $\boldsymbol{P}$. hamadryas & 0.01 & 0.01 & 1 & 0.621 & 0.751 & 0.331 \\
\hline $\boldsymbol{P}$. kindae & 0.01 & $\mathbf{0 . 1 6}$ & 0.01 & 1 & 0.639 & 0.761 \\
\hline $\boldsymbol{P}$. ursinus & 0.01 & 0.01 & 0.01 & 0.01 & 1 & 0.593 \\
\hline
\end{tabular}

Table 6: Niche Overlap with Schoener's D

Above the diagonal is Schoener's D observed values, below the diagonal are the corresponding p-values. Most pair-wise comparisons fell significantly below 100 randomized values, indicating that there is little niche overlap. Two comparisons, both including hamadryas baboons, fell within the range of random values.

\begin{tabular}{|c|c|c|c|c|c|c|}
\hline SPECIES & P. anubis & $\begin{array}{c}P . \\
\text { cynocephalus }\end{array}$ & P. papio & $\begin{array}{c}P . \\
\text { hamadryas }\end{array}$ & P. kindae & P. ursinus \\
\hline P. anubis & 1 & 0.532 & 0.287 & 0.656 & 0.268 & 0.211 \\
\hline $\begin{array}{l}P . \\
\text { cynocephalus }\end{array}$ & 0.04 & 1 & 0.208 & 0.583 & 0.278 & 0.362 \\
\hline P. papio & 0.01 & 0.01 & 1 & 0.332 & 0.446 & 0.112 \\
\hline P. hamadryas & 0.22 & 0.14 & 0.01 & 1 & 0.400 & 0.436 \\
\hline P. kindae & 0.01 & 0.01 & 0.01 & 0.01 & 1 & 0.373 \\
\hline P. ursinus & 0.01 & 0.01 & 0.01 & 0.01 & 0.01 & 1 \\
\hline
\end{tabular}




\section{References:}

Alberts, Susan C., and Jeanne Altmann. 2001. "Immigration and Hybridization Patterns of Yellow and Anubis Baboons in and around Amboseli, Kenya." American Journal of Primatology 53 (4): 139-54.

Altmann, Stuart A., and Jeanne Altmann. 1973. Baboon Ecology: African Field Research. Chicago: University of Chicago Press.

Bergman, Thore J., and Jacinta C. Beehner. 2004. "Social System of a Hybrid Baboon Group (Papio Anubis x P. Hamadryas)." International Journal of Primatology 25 (6): 1313-30. doi:10.1023/b:ijop.0000043964.01085.dc.

Bergman, Thore J., and Jacinta C. Beehner. 2003. Hybrid zones and sexual selection: insights from the Awash baboon hybrid zone (Papio hamadryas anubis X P. h. hamadryas). In Sexual selection and reproductive competition in primates: new insights and directions, edited by Kappeler, Peter M., and Carel P. Van Schaik, 503-537. Norman, OK: American Society of Primatologists.

Bergman, Thore J., Jane E. Phillips-Conroy, and Clifford J. Jolly. 2008. "Behavioral Variation and Reproductive Success of Male Baboons (Papio Anubis x Papio Hamadryas) in a Hybrid Social Group." American Journal of Primatology 70 (2): 136-47.

Blair, M. E., E. J. Sterling, M. Dusch, C. J. Raxworthy, and R. G. Pearson. 2013. "Ecological Divergence and Speciation between Lemur (Eulemur) Sister Species in Madagascar." Journal of Evolutionary Biology 26 (8): 1790-1801. doi:10.1111/jeb.12179.

Burrell AS. 2008. Phylogenetics and population genetics of Central African baboons. PhD Thesis. New York: New York University.

Burrell, Andrew S., Clifford J. Jolly, Anthony J. Tosi, and Todd R. Disotell. 2009. "Mitochondrial Evidence for the Hybrid Origin of the Kipunji, Rungwecebus Kipunji (Primates: Papionini)." Molecular Phylogenetics and Evolution 51 (2): 340-48. doi:10.1016/j.ympev.2009.02.004.

Chowdhury, Shahrina, Mathew Pines, Julian Saunders, and Larissa Swedell. 2015. "The Adaptive Value of Secondary Males in the Polygynous Multi-Level Society of Hamadryas Baboons." American Journal of Physical Anthropology 158 (3): 501-13. doi:10.1002/ajpa.22804.

Deshmukh IK (1984) "A common relationship between precipitation and grassland peak biomass for East and southern Africa." African Journal Ecology 22:181-186 
Dunbar, R. I. M., and Patsy Dunbar. 1974. "On Hybridization between Theropithecus Gelada and Papio Anubis in the Wild." Journal of Human Evolution 3 (3): 187-92. doi:10.1016/0047-2484(74)90176-6.

Elith, Jane, Catherine H. Graham, Robert P. Anderson, Miroslav DudÃ-k, Simon Ferrier, Antoine Guisan, Robert J. Hijmans, Falk Huettmann, John R. Leathwick, Anthony Lehmann, Jin Li, Lucia G. Lohmann, Bette A. Loiselle, Glenn Manion, Craig Moritz, Miguel Nakamura, Yoshinori Nakazawa, Jacob Mcc. M. Overton, A. Townsend Peterson, Steven J. Phillips, Karen Richardson, Ricardo Scachetti-Pereira, Robert E. Schapire, Jorge SoberÃ ${ }^{3} n$, Stephen Williams, Mary S. Wisz, and Niklaus E. Zimmermann. 2006. "Novel Methods Improve Prediction of Speciesâ $\square^{\mathrm{TM}}$ Distributions from Occurrence Data." Ecography 29 (2): 129-51. 10.1111/j.2006.0906-7590.04596.x.

Frost, Stephen R., Leslie F. Marcus, Fred L. Bookstein, David P. Reddy, and Eric Delson. 2003. "Cranial Allometry, Phylogeography, and Systematics of Large-Bodied Papionins (Primates: Cercopithecinae) Inferred from Geometric Morphometric Analysis of Landmark Data." The Anatomical Record 275A (2): 1048-72. doi:10.1002/ar.a.10112.

Gilbert, Christopher Charles. 2008. African papionin phylogenetic history and PlioPleistocene biogeography. State University of New York at Stony Brook.

Gilbert, Christopher C., Christine M. Steininger, Job M. Kibii, and Lee R. Berger. 2015. "Papio Cranium from the Hominin-Bearing Site of Malapa: Implications for the Evolution of Modern Baboon Cranial Morphology and South African Plio-Pleistocene Biochronology." Plos One 10 (8). doi:10.1371/journal.pone.0133361.

Groves, Colin P. Primate Taxonomy. 2001. Washington: Smithsonian Institution Press.

Grubb P, Butyinski TM, Oates JF, Bearder SK, Disotell TR, Groves CP, Struhsaker CP (2003) Assessment of the diversity of African primates. International Journal of Primatology 24: 1301-1357.

Henzi, Peter, and Louise Barrett. 2003. "Evolutionary Ecology, Sexual Conflict, and Behavioral Differentiation among Baboon Populations." Evolutionary Anthropology: Issues, News, and Reviews (12) 5: 217-30. doi:10.1002/evan.10121.

Higham, James P., Ymke Warren, Jeremiah Adanu, Buba N. Umaru, Ann M. Maclarnon, Volker Sommer, and Caroline Ross. 2009. "Living on the Edge: Life-History of Olive Baboons at Gashaka-Gumti National Park, Nigeria." American Journal of Primatology 71 (4): 293-304. doi:10.1002/ajp.20651.

Hijmans, Robert J., Susan E. Cameron, Juan L. Parra, Peter G. Jones, and Andy Jarvis. 2005. "Very High Resolution Interpolated Climate Surfaces for Global Land Areas." International Journal of Climatology 25 (15): 1965-78. doi:10.1002/joc.1276. 
Hill, William Charles Osman. 1970. Primates: Comparative Anatomy and Taxonomy. Edinburgh: Edinburgh University Press.

Hill, R. A., L. Barrett, D. Gaynor, T. Weingrill, P. Dixon, H. Payne, S. P. Henzi. "Day length, latitude and behavioural (in) flexibility in baboons (Papio cynocephalus ursinus)." Behavioral Ecology and Sociobiology 53.5 (2003): 278-286.

Hourou, HN le. 1984. "Rain use efficiency: a unifying concept in arid land ecology." Journal of Arid Environment 7:213-247

Hoffman, Tali S., and M Justin O'riain. 2012. "Monkey Management: Using Spatial Ecology to Understand the Extent and Severity of Human-Baboon Conflict in the Cape Peninsula, South Africa." Ecology and Society 17 (3). doi:10.5751/es-04882-170313.

Jolly, Clifford J., Tamsin Woolley-Barker, Shimelis Beyene, Todd R. Disotell, and Jane E. Phillips-Conroy. 1997. "Intergeneric hybrid baboons." International Journal of Primatology (18) 4: 597-627.

Jolly, Clifford J., Andrew S. Burrell, Jane E. Phillips-Conroy, Christina Bergey, and Jeffrey Rogers. 2010. "Kinda Baboons (Papio Kindae) and Grayfoot Chacma Baboons (P. Ursinus Griseipes) Hybridize in the Kafue River Valley, Zambia." American Journal of Primatology 73 (3): 291-303. doi:10.1002/ajp.20896.

Jolly, Clifford J. 1993. "Species, Subspecies, and Baboon Systematics." Species, Species Concepts and Primate Evolution: 67-107. doi:10.1007/978-1-4899-3745-2_4.

Jolly, Clifford J. 2007. "Baboons, mandrills, and mangabeys: Afro-Papionin socioecology in a phylogenetic perspective." In Primates in perspective, edited by Campbell, Christina J., Agustín Fuentes, Katherine C. MacKinnon, Melissa Panger, and S. K. Bearder, 240-251. New York: Oxford University Press.

Jones, Clara B. 2003. "Hybrid Zones and Sexual Selection: Insights from the Awash Baboon Hybrid Zone (Papio Hamadryas Anubis x P. h. Hamadryas)." In Sexual Selection and Reproductive Competition in Primates: New Perspectives and Directions, edited by Jones, Clara B., 503-537. Norman, OK: American Society of Primatologists.

Kamilar, Jason M. 2006. "Geographic variation in savanna baboon (Papio) ecology and its taxonomic and evolutionary implications." In Primate biogeography, edited by Tuttle, Russell H., and Shawn M. Lehman, 169-200. New York, NY: Springer Science+Business Media, LLC.

Kamilar, Jason M., and Stacey R. Tecot. 2015. "Anthropogenic and Climatic Effects on the Distribution of Eulemur Species: An Ecological Niche Modeling Approach." International Journal of Primatology 37 (1): 47-68. doi:10.1007/s10764-015-9875-8. 
Kamilar, Jason, Marina B. Blanco, and Kathleen M. Muldoon. 2016. "Ecological Niche Modeling of Mouse Lemurs (Microcebus Spp.) and Its Implications for Their Species Diversity and Biogeography." In The Dwarf and Mouse Lemurs of Madagascar Biology, Behavior, and Conservation Biogeography of the Cheirogaleidae, edited by Lehman, Shawn M., Ute Radespiel, and Elke Zimmermann, 449-61. Cambridge, UK: Cambridge University Press.

Kingdon, Jonathan. 2015. The Kingdon Field Guide to African Mammals. Princeton, NJ: Princeton University Press.

Kummer H (1968) Social Organization of Hamadryas Baboons: A Field Study (Univ of Chicago Press, Chicago). 5. Abegglen J (1984) On Socialization in Hamadryas Baboons: A Field Study (Bucknell Univ Press, Lewisburg, PA).

Kunz, Britta Kerstin, and Karl Eduard Linsenmair. 2008. "The Role of the Olive Baboon (Papio Anubis, Cercopithecidae) as Seed Disperser in a Savanna-Forest Mosaic of West Africa." Journal of Tropical Ecology 24 (3): 235-46. doi:10.1017/s0266467408005014.

Mantel, Nathan. "The detection of disease clustering and a generalized regression approach." Cancer research 27.2 Part 1 (1967): 209-220

Newman, Timothy K., Clifford J. Jolly, and Jeffrey Rogers. 2004. "Mitochondrial Phylogeny and Systematics of Baboons (Papio)." American Journal of Physical Anthropology 124 (1): 17-27. doi:10.1002/ajpa.10340.

Peterson, A. T. 1999. "Conservatism of Ecological Niches in Evolutionary Time." Science 285 (5431): 1265-67. doi:10.1126/science.285.5431.1265.

Phillips, Steven J., and Miroslav DudÃ-k. 2008. "Modeling of Species Distributions with Maxent: New Extensions and a Comprehensive Evaluation." Ecography: 161-175. doi:10.1111/j.0906-7590.2007.5203.

Phillips, Steven J., Robert P. Anderson, and Robert E. Schapire. 2006. "Maximum Entropy Modeling of Species Geographic Distributions." Ecological Modelling 190 (3-4): 231-259. doi:10.1016/j.ecolmodel.2005.03.026.

Raxworthy, Christopher J., Colleen M. Ingram, Nirhy Rabibisoa, Richard G. Pearson, and John Weins. 2007. "Applications of Ecological Niche Modeling for Species

Delimitation: A Review and Empirical Evaluation Using Day Geckos (Phelsuma) from Madagascar." Systematic Biology 56 (6): 907-23. doi:10.1080/10635150701775111.

Roberts, T. E., T. R. B. Davenport, K. B. P. Hildebrandt, T. Jones, W. T. Stanley, E. J. Sargis, and L. E. Olson. 2009. "The Biogeography of Introgression in the Critically 
Endangered African Monkey Rungwecebus Kipunji." Biology Letters 6 (2): 233-237. doi:10.1098/rsbl.2009.0741.

Schoener, Thomas W. 1968. "The Anolis Lizards of Bimini: Resource Partitioning in a Complex Fauna." Ecology 49 (4): 704-26. doi:10.2307/1935534.

Schreier, Amy L., and Larissa Swedell. 2012. "Ecology and Sociality in a Multilevel Society: Ecological Determinants of Spatial Cohesion in Hamadryas Baboons." American Journal of Physical Anthropology 148 (4): 580-588. doi:10.1002/ajpa.22076.

Schreier, Amy L., and Larissa Swedell. 2009. "The Fourth Level of Social Structure in a Multi-Level Society: Ecological and Social Functions of Clans in Hamadryas Baboons." American Journal of Primatology 71 (11): 948-55. doi:10.1002/ajp.20736.

Shotake, Takayoshi. 1981. "Population Genetical Study of Natural Hybridization Between Papio Anubis and P. Hamadryas." Primates 22 (3): 285-308. doi:10.1007/bf02381572.

Stone, Olivia M. L., Shawn W. Laffan, Darren Curnoe, Andy I. R. Herries.. 2013. "The Spatial Distribution of Chacma Baboon (Papio Ursinus) Habitat Based on an Environmental Envelope Model." International Journal of Primatology 34 (2): 407-22. doi:10.1007/s10764-013-9669-9.

Stone, Olivia ML, Shawn W. Laffan, Darren Curnoe, lan Rushworth, Andy I. R. Herries. 2012. "Distribution and population estimate for the chacma baboon (Papio ursinus) in KwaZulu-Natal, South Africa." Primates 53.4: 337-344.

Szalay, Frederick S., and Eric Delson. 1979. Evolutionary History of the Primates. New York: Academic Press.

Tung, J., M. J. E. Charpentier, D. A. Garfield, J. Altmann, and S. C. Alberts. 2008. "Genetic Evidence Reveals Temporal Change in Hybridization Patterns in a Wild Baboon Population." Molecular Ecology 17 (8): 1998-2011. doi:10.1111/j.1365294x.2008.03723.

Warren, Dan L., and Stephanie N. Seifert. 2011. "Ecological Niche Modeling in Maxent: the Importance of Model Complexity and the Performance of Model Selection Criteria." Ecological Applications 21 (2): 335-42. doi:10.1890/10-1171.1.

Warren, Dan L., Richard E. Glor, and Michael Turelli. 2010. "ENMTools: a Toolbox for Comparative Studies of Environmental Niche Models." Ecography. doi:10.1111/j.16000587.2009.06142. 
Warren, Dan L., Richard E. Glor, and Michael Turelli. 2008. "Environmental Niche Equivalency Versus Conservatism: Quantitative Approaches To Niche Evolution." Evolution 62 (11): 2868-83. doi:10.1111/j.1558-5646.2008.00482.

Winder, Isabelle C. 2014. "The Biogeography of the Papio Baboons: A GIS-Based Analysis of Range Characteristics and Variability." Folia Primatologica 85 (5): 292-318. doi:10.1159/000362545.

Yackulic, Charles B., et al. 2012. "Presence-Only Modelling Using MAXENT: When Can We Trust the Inferences?" Methods in Ecology and Evolution 4 (3): 236-43.

doi:10.1111/2041-210x.12004.

Zinner, Dietmar, et al. 2012. "Baboon Phylogeny as Inferred from Complete Mitochondrial Genomes." American Journal of Physical Anthropology 150 (1): 133-40. doi:10.1002/ajpa.22185.

Zinner, Dietmar, et al. 2009. "Mitochondrial Phylogeography of Baboons (Papio Spp.) Indication for Introgressive Hybridization?” BMC Evolutionary Biology 9 (1): 83. doi:10.1186/1471-2148-9-83.

Zinner, Dietmar, et al. 2009b. "Is the New Primate Genus Rungwecebus a Baboon?" PLoS ONE 4 (3). doi:10.1371/journal.pone.0004859.

Zinner, D., F. Pelaez, and F. Torkler. 2001. "Distribution and habitat associations of baboons (Papio hamadryas) in Central Eritrea." International Journal of Primatology 22 (3): 397-413. 